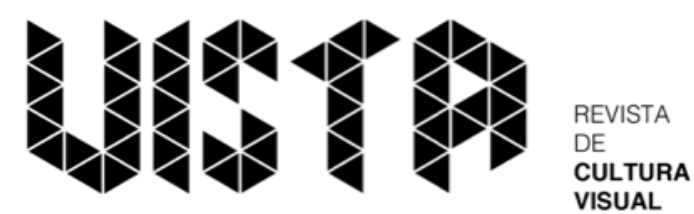

\section{Discursos cruzados - memória e arquivo, individual e coletivo}

Nuno Pinheiro

\section{Resumo:}

A memória coletiva é um terreno disputado e com influência na nossa memória individual, sustenta-se numa série de locais da memória que incluem, mas não se limitam ao arquivo. Esse arquivo é também a base da história oficial. Essa memória recompõe-se com as necessidades sociais. A História, enquanto disciplina, deveria estabilizar a memória, mas é também mutável. A memória individual é servida por outros materiais e locais da memória, entre os quais o álbum de família. Esta memória individual é igualmente passível de desmemorização e rememorização de acordo com as necessidades emocionais e materiais. Para ela o álbum de fotografias contribui com registo de pessoas e ocasiões ausentes do arquivo oficial.

Uma nova história mais abrangente em temas e fontes necessita da incorporação da memória pessoal e familiar na memória coletiva e do arquivo e álbum de família em museus e arquivos locais.

Palavras-chave: arquivo; memória; história; imagem.

\footnotetext{
Abstract:

Collective memory is a disputed field, influencing our individual memory. It is supported by a number of places of memory including, but not limited to the archive. The archive is the support of official history. Collective memory is rebuilt according to social needs. It should be made established by history, however history does also change.

There are other materials for the individual and family memory, including family album. This memory can also be destructed and reconstructed, according to family emotional and material needs. Family album includes records of people and occasions absent from official archives.
} 
A new history would encompass broader themes and sources and will need to incorporate personal and family albums and archives in local museums and archives.

Keywords: archive, memory, image, history.

\section{Introdução}

Este texto remete para a realidade dos arquivos existente em meados dos anos 90 , quando iniciei os meus estudos baseados em fotografias. $\mathrm{Na}$ altura, no processo de construção da minha dissertação de mestrado (Pinheiro, 1997) eram poucos os arquivos dedicados à imagem e o seu funcionamento era muito deficiente. O Arquivo Fotográfico da Câmara Municipal de Lisboa tinha novas instalações e possibilidade de pesquisa informática numa bem equipada e confortável sala de leitura. Havia outros arquivos, um pomposamente chamado Arquivo Nacional de Fotografia estava organizado de forma a dificultar ao máximo, para não dizer impossibilitar, o trabalho do investigador. No Palácio Foz estavam sediados alguns arquivos importantes, resultantes da extinção do jornal diário "O Século" e, apesar da falta de instrumentos de pesquisa, esta era possível, graças à dedicação dos que lá trabalhavam. Ainda não existia o Centro Português de Fotografia o panorama fora de Lisboa era pior. Alguns arquivos e museus municipais tinham fotografias antigas, mas não estavam organizadas. A disponibilidade ou não de fotografias acabou por ser determinante para o rumo e âmbito do trabalho.

Sou historiador e os historiadores trabalham com fontes, quase sempre escritas. A história faz-se de palavras, ainda muito pouco de imagens. A utilização da imagem como fonte é recente e ainda marginal. Não tenho dúvidas de que a imagem será fundamental para o historiador do futuro que terá à sua disposição não só os textos, como as fotografias e os vídeos das pessoas, situações e acontecimentos.

Nem a coincidência temporal entre a invenção, ou melhor, as várias invenções da fotografia, e da história moderna e científica, baseada em arquivos, na década de 1830, colocou a fotografia na posição de fonte para a história. A História tem sido sobretudo construída a partir de fontes escritas, mas vivemos numa sociedade em que a imagem é cada vez mais importante. Se a história precisa dos arquivos, a fotografia está condenada a produzi-los e poderá estar nos arquivos privados e familiares, assim como nos arquivos públicos ou oficiais.

Um dos trabalhos que me inspiraram e que coloca a questão dos arquivos privados e públicos, é o trabalho monumental dirigido por Tenfelde (1994), sobre as fotografias da Krupp. Esta empresa construiu um arquivo fotográfico que era ao mesmo tempo familiar 
e empresarial. $\mathrm{O}$ arquivo que se começou a construir em 1865 chegou às 500 mil imagens, incluindo imagens de edifícios e equipamentos, trabalho e também retratos da família Krupp e de trabalhadores. É interessante esta combinação entre o arquivo mais público, ilustrando o trabalho das fábricas, e o seu lado privado, com fotografias da família. A família era a dos proprietários da empresa e o arquivo servia os fins desta família, quer na sua função empresarial e económica, quer no seu lado privado e familiar. As fronteiras entre o privado e o público não são imutáveis, e este arquivo iniciase numa altura em que estava em voga a Carte de Visite, fotografias que eram entregues às pessoas com que havia relacionamento e que serviriam tanto para situações públicas, como privadas.

Tradicionalmente existem discursos separados e bastante estanques sobre a memória individual e a memória coletiva. Neste texto centrado na importância da imagem para a memória, a proposta é compreender que memória individual e memória coletiva são permeáveis, comunicando entre si. Considerando os arquivos como repositórios da memória também alguns sê-lo-ão da memória coletiva, outros da memória pessoal, individual e familiar. A permeabilidade das memórias deve levar ao cruzamento de arquivos, à criação de formas de incorporar as memórias individuais, familiares e de grupo, nos grandes arquivos coletivos. A entrada do arquivo privado no público só é possível com a proliferação de arquivos locais.

Mas serão estes discursos cruzados entre a memória individual e a memória coletiva, entre o arquivo privado e o arquivo público possíveis? E sendo-o, como pode o arquivo público incorporar as memórias e arquivos privados?

\section{Memória individual e memória coletiva}

A memória coletiva é uma das componentes centrais da estrutura ideológica da sociedade. Permite-lhe cimentar a coesão, já que é partilhada por um determinado grupo, familiar, religioso, local, nacional (Halbwachs, s.d.). Pierre Nora, no artigo sobre memória coletiva em $A$ Nova História aprofunda o conceito: "a memória coletiva é a recordação ou o conjunto de recordações, conscientes ou não, de uma experiência vivida e/ou mitificada, por uma coletividade viva de cuja identidade faz parte integrante o sentimento do passado" (Nora, 1978: 451).

Para o mesmo autor a memória coletiva é o que fica do passado, da vivência de grupos maiores ou menores, grupos que podem ser à escala nacional, de ideologias políticas ou religiosas, mas também mais limitados como gerações e movimentos minoritários 
(Nora, 1978: 451). A memória evolui, sendo apagada e reconstruída em função das necessidades do momento.

A multiplicação de grupos sociais que se autonomizam por meio da recuperação do seu passado, leva à multiplicação de memórias coletivas. Países, tendências políticas, religiões, modalidades e clubes desportivos, localidades, escolas, turmas e até famílias constroem a sua memória coletiva que pode ser antagónica com a de outros grupos.

A memória coletiva vai também fazer parte da memória individual, na medida em que o indivíduo faz parte do grupo e com ele partilha esta parte da memória. Muitas vezes as imagens são fundamentais na construção desta memória. Imagens partilhadas, difundidas, vistas por todos e como tal incorporadas na memória coletiva, farão parte das memórias individuais.

A memória individual tem sido sobretudo um campo de estudo dos psicólogos, interessando-nos sobretudo a relação entre a memória individual e coletiva. Vimos acima que a memória coletiva influencia e é incorporada na memória individual, mas não teremos o contrário? As experiências individuais sendo semelhantes em indivíduos do mesmo grupo e do mesmo tempo, não acabarão por fazer parte da memória coletiva? Tal como a memória coletiva, a memória individual está sujeita ao esquecimento, desmemorização e recomposição, de acordo com as necessidades do indivíduo, mas também de acordo com as necessidades da sociedade. Esta memória também incorpora a pertença ao grupo e à sua memória. Memória individual e coletiva interpenetram-se e constroem-se mutuamente.

Ao contrário da memória coletiva em que há limites à desmemorização e à reconstrução, a memória individual pode sempre ser recriada. Os limites da reconstrução da memória coletiva, da rememoração, são os das relações de força sociais, que abordaremos à frente.

A história seria uma estabilização da memória. Depois de interpretada, "cientifizada" e estabelecida não haveria lugar a novas interpretações, mas sabemos que não é assim. A história também se reescreve em função das necessidades sociais do seu tempo. Um exemplo português: a história da Expansão Portuguesa passou a ter uma visão mais ligada à economia depois dos trabalhos de Magalhães Godinho e uma nova ideia de "encontro de culturas" depois da descolonização. E estamos a falar de uma história de tempos bastante remotos. Se nos aproximarmos no tempo maiores são as possibilidades de ver tais alterações. Outro exemplo é a Revolução Francesa, momento fundador da República Francesa que tinha uma visão positiva numa longa tradição historiográfica, para, por altura do seu bicentenário François Furet apresentar uma visão que contrariava o discurso vigente que considera a Revolução Francesa como ato fundador das sociedades democráticas, para se concentrar nas questões do terror. 
O virar da história da expansão para a economia implicou novas fontes e novos arquivos, alguns dos quais eram privados. Os roles de compras existentes nos arquivos das misericórdias foram essenciais para a compreensão da evolução dos preços. Já a mudança de ponto de vista sobre a História da Revolução Francesa é sobretudo uma mudança ideológica, sem que para isso tenham contribuído novas fontes ou arquivos.

\section{Fotografia e memória}

Para Susan Sontag "fotografar é conferir importância" (Sontag, 1986: 34), uma vez que tudo é fotografável, mas nem tudo é fotografado, a fotografia dá, alguma forma, a medida da importância das coisas. A fotografia é também um reflexo do gosto de uma época, que se forma em função da estrutura social em cada etapa da sua evolução (Freund, 1974).

Mas na ordenação destes fragmentos, que, em si, podem não explicar muito é que está o trabalho do historiador, tendo em conta que tanto os assuntos, como as formas de os representar são importantes, já que aí temos a medida do gosto e da importância que determinada época dava às coisas.

De comum com a história, a fotografia, tem o tempo, o passado, mas esta foca-se num tempo prolongado em que se procura a ação, a mudança. Mas estas não são aparentes numa imagem isolada e só podem ser apercebidas na acumulação das fotografias de forma a possibilitar uma visão comparativa.

Produzir memória é um objetivo confesso da atividade fotográfica. Neste sentido, a fotografia não é completamente nova, correspondendo a uma massificação dessa produção. As classes dominantes tinham uma produção de retratos pintados muito antes de 1840. A massificação tornada possível pela fotografia não se faz notar só na ascensão de novas camadas sociais à possibilidade de produção de uma memória visual, mas igualmente nas situações dessa produção.

Para Freund, essa ascensão de novas camadas sociais à produção de memória não é mais do que um sinal da sua ascensão a uma maior significação política e social (Freund, 1974), já que a principal tarefa da fotografia era a de satisfazer estas necessidades de representação (Freund, 1978).

Cria-se todo um código de ocasiões em relação às quais a produção de memória se torna obrigatória, ou mesmo, em que esta acaba por ser incorporada nos próprios rituais, a fotografia dos casamentos é o exemplo mais evidente. A fotografia estará presente nas ocasiões significativas que se tornam ainda mais significativas pela presença da fotografia. 
Esta memória funciona sobretudo ao nível da família, ou de outro grupo que se the possa equiparar, construindo "uma crónica de si mesma, uma série, portátil de imagens que testemunha a sua coesão" (Sontag, 1986: 18) O álbum de fotografias é a materialização dessa série de imagens, não importa muito se são folhas de papel com fotografias coladas, ou se é um dossier num telemóvel. Será mais efémero o que se guarda em aparelhos de vida limitada, mas esse é um problema recente.

A memória pretende ser individualizada, entendendo-se a família ou o grupo como indivíduo, a presença dos rituais e códigos estandardizados diminui o seu lado indivíduo para se tornar sobretudo na memória de uma sociedade.

É preciso ter consciência, ao trabalhar com fotografias, que estas foram feitas com o objetivo de ficarem na memória. Mesmo quando são feitas para documentos administrativos representam um indivíduo que tenta dar de si a imagem que quer. A fotografia de identificação é um bom exemplo disso. Até há pouco havia uma distinção entre a imagem de identificação do cidadão comum e a imagem de identificação policial. Nesta última os padrões eram muito mais rígidos em relação à pose e ao ângulo de visão. Uma fotografia de identificação prisional não teria, seguramente, lugar no álbum de família, mas apenas no arquivo oficial para o qual foi produzida. Durante 100 anos as fotografias de identificação deram a fotógrafo e fotografado alguma margem para tentar parecer o melhor possível e ter uma imagem esteticamente agradável, com lugar no álbum de família. Recentemente as normas e a vontade de normalização aproximaram a fotografia de identificação do cidadão comum da fotografia policial e estas não têm lugar no álbum de família.

A massificação da fotografia permitiu que se mantivesse alguma forma de memória em situações da vida humana que não eram objeto de nenhuma forma de registo. Isto aplica-se muito a aspetos da vida privada e familiar que têm sido o próprio objeto da fotografia (Bourdieu, 1965) e que não é, geralmente, alvo da produção de mais documentos.

Mas pode-se perguntar qual é a memória produzida numa fotografia, ou, talvez, de uma forma mais rigorosa, de quem é a memória que fica registada? Voltamos a Barthes (1981: 29) que diz:

Aí se cruzam, se confrontam e se deformam quatro imaginários. Perante a objetiva, eu sou simultaneamente aquele que eu julgo ser, aquele que eu gostaria que os outros julgassem que eu fosse, aquele que o fotógrafo julga que sou e aquele de quem ele se serve para exibir a sua arte.

Além de entrar em aspetos da vida, especialmente privada, em que não abundam outros documentos, a fotografia tem-se vindo a produzir e a guardar em quantidades que não 
eram imagináveis noutros documentos. Essa quantidade tem vindo a crescer. No século XIX cada fotografia era o resultado de um processo caro e moroso. Chapas de vidro, muitas vezes preparadas no momento.

Em finais do século XIX surge a possibilidade de utilizar rolos, mais simples, mais barato, a revelação separa-se do ato de fotografar. Fotografa-se e manda-se revelar ("We do the rest", dizia-se na publicidade da Kodak). O número de praticantes da fotografia cresceu enormemente. $E$ foi crescendo ao longo do século $X X$, até porque nos países desenvolvidos os rendimentos iam crescendo e a sociedade de consumo ganhava terreno. Com a fotografia (e estou a pensar naquela que encontramos nos álbuns familiares) também se podem ver os consumos e aspetos materiais que para épocas muito mais recuadas são objeto da arqueologia. No início do século XXI assistese a outra expansão da fotografia. A popularização do digital e, mais ainda, a presença de câmaras nos omnipresentes telemóveis leva a uma nova explosão do número de imagens e das ocasiões em que estas são feitas.

Talvez mais importante que o crescimento do número de imagens sejam as possibilidades de difusão que cria. Esta difusão pode-se fazer por grupos restritos, já que estes equipamentos permitem o envio de imagens para os mais próximos, mas pode também abranger grupos mais alargados, possível com as redes sociais. Um objetivo pode ser mesmo o tornar a vida pessoal numa narrativa de difusão muito grande, passando por muitas partilhas, "viral" é a expressão usada.

Um grande número de imagens não significa a conservação dessas imagens, e esse é um problema que se coloca hoje. As imagens circulam em meios digitais, raramente são objeto de impressão e o seu armazenamento é um problema por resolver. Uma coisa é certa, estas imagens não se irão manter por inércia, será necessário um esforço para a sua conservação.

Foi a partir dos anos 1840 que a fotografia se tornou um instrumento privilegiado de construção da memória, "um suporte de rememoração que renova a nostalgia" (Corbin, 1990: 426). Não é para admirar que, já no Século XX, o maior fabricante de material fotográfico, a Kodak, tenha colocado a construção de memória na sua publicidade e até nos seus slogans e jingles publicitários. A construção e a preservação de memória tornaram-se, até, no principal argumento deste fabricante na luta constante contra os outros fabricantes que fornecem produtos semelhantes. A ideia da sua publicidade era: - "se não utilizar os nossos produtos as suas memórias não se vão conservar". A fotografia, graças à sua precisão foi vista, rapidamente como uma forma de ultrapassar as limitações da volúvel e falível memória humana (Osherson, 1990). 
O que torna diferente a produção de memória por meio da fotografia é a existência de uma atividade que a isso se dedica de forma quase exclusiva. Ao contrário de outras formas de produzir memória, em que esta produção é uma consequência, na fotografia a produção da memória é um objetivo deliberado e assumido. Pode-se incluir, assim, a fotografia na série de ritos de memória que se destinam a prolongar a felicidade (MartinFugier, 1990). Nial Ferguson observa que, segundo Marx, os homens fazem a sua história, mas sem saber que a fazem, enquanto com a fotografia a fazem de forma deliberada (Ferguson, 1997). Desde a Carte de Visite dos anos 1860 que a memória fotográfica é produzida, potencialmente, sobre toda a população. Todos queriam ter o seu retrato, para que essa produção de memória incidisse sobre eles.

A partir do momento em que a fotografia se torna mais barata e fácil de produzir em grandes quantidades, nos anos 1860, que essas memórias visuais deixam de ser feitas exclusivamente para a exposição ou o desfrute em casa do retratado, para serem objetos destinados à oferta e circulação dentro do círculo de relações pessoais, familiares e profissionais deste. É dessa circulação que nasce o hábito da coleção, uma coleção que era, não só a das fotografias das pessoas próximas, como a de pessoas célebres, supostamente, aquelas que despertavam admiração. Uma ávida colecionadora de fotografias seria a Rainha Vitória que reuniu 110 álbuns fotográficos da sua família, numerosa e muito espalhada (Briggs, 1989).

Estes álbuns que incorporavam personagens públicas, geralmente da política ou da realeza, significavam a entrada da vida pública na privada e na memória individual e familiar. Representam uma memória familiar, em que além das relações pessoais e familiares (Martin-Fugier, 1990), também se demonstram gostos artísticos ou preferências políticas, já que os retratos de dirigentes políticos nacionais e estrangeiros eram muito populares e tinham o seu lugar nesses álbuns. Aquelas personagens que eram incluídas nesses álbuns não seriam um fruto do acaso, mas sim da admiração ou afeto que por elas era demonstrado.

As fronteiras entre o público e o privado foram-se redefinindo e a partir da Grande Guerra os álbuns de família vão-se limitando aos mais próximos. A haver lugar para celebridades era agora num espaço à parte onde se podiam colecionar imagens de locais e monumentos, mas também de pessoas célebres, só que já não eram políticos e cabeças coroadas, mas sim estrelas de cinema, música e desporto. O mundo tinha mudado e a confiança nos governantes desaparecido.

$\mathrm{Na}$ mais recente omnipresença das imagens, as personagens públicas voltam a ter um lugar no álbum de família, pelo menos no álbum virtual. As selfies com artistas, músicos, desportistas são comuns, e até temos de novo os políticos, como o Presidente Marcelo Rebelo de Sousa, nos álbuns dos telemóveis e das redes sociais. 


\section{Sistematização da memória}

A fotografia integra-se, ao mesmo tempo, em duas "modas" oitocentistas. A de colecionar e a da produção de memória que também passa pela escrita de diários e livros de memórias e viagens.

A coleção de fotografias tinha um local próprio de exposição, o álbum, onde as fotografias encontravam o seu lugar na hierarquia das relações familiares e das personalidades importantes. O álbum ganha uma enorme importância na vida e na representação social da família, tornando-se, em si, um objeto de representação social (Linkman, 1993), mas também uma forma de aumentar a coesão do grupo ameaçada pela evolução económica (Corbin, 1990). É um objeto em que se deposita a memória e a sua revisão é uma forma de voltar a passar pela memória familiar, já que nele se regista a passagem do tempo, a evolução da criança, a história da família. A sua importância deriva da sua inserção nos ritos fundamentais da vida familiar (Hirsh, 1997). Torna-se simbólico de alguma forma de recordar. Silvia Gherardi (1995) compara a sua revisão de materiais feministas com a de um álbum de família. Esse álbum fotográfico incluí não só as fotografias da família, como as de celebridades, que são vendidas aos milhares. Encadernado de uma forma que fazia lembrar as bíblias, o álbum valia por si, como objeto de luxo, dando prestígio ao seu possuidor, tinha o seu pequeno aspeto de veneração religiosa. Ligado ao espaço doméstico e à família, o álbum acaba por ter a sua manutenção, decoração e atualização incluídas nas tarefas femininas.

Dentro do álbum, inseridos nos espaços a isso destinados, havia retratos. Estes, em especial desde a Carte de Visite, tinham formatos normalizados. Os retratos individuais também correspondiam ao mesmo tipo de desejos que o álbum completo: "O retrato é portanto um signo cujo objetivo é tanto a descrição de um indivíduo e a inscrição da identidade social, mas, ao mesmo tempo, também é uma mercadoria, um luxo, um adorno, cuja posse confere estatuto por si" (Tagg, 1998: 37). A fotografia ganha, assim uma forte carga simbólica, ultrapassando a simples reprodução de sujeitos, objetos e acontecimentos (Fabri, 1997: 37). 


\section{Memória das pessoas e das ocasiões}

Nem todas as fotografias acabavam nos álbuns, algumas tinham uma importância ainda maior que obrigava a que estivessem em exposição. Era o caso já referido da "fotografia da boda, memória visual da família, colocada num bom local em casa, dá a medida do parentesco" (Lequin, 1998: 28). Isto acontecia, especialmente porque, quando havia fotografias com os convidados, a sua disposição era feita segundo a medida da proximidade do parentesco.

Uma das características do estabelecimento de uma memória familiar por meio da fotografia é que essa memória se constrói em momentos alegres. É o contrário do que Walter Benjamin dizia, já que este autor defendia que a História tinha que ser uma história triste (Felman, 1999).

A tristeza deste autor tinha a ver com a guerra, em especial com a $1^{\text {a }}$ Guerra Mundial, mas, até essa foi transformada, por meio da fotografia, num acontecimento alegre, ou pelo menos, um pouco menos triste, já que omitiu os momentos e as situações mais sangrentas. Inúmeros álbuns de fotografias feitas por militares, por vezes vencendo a proibição imposta pelas autoridades militares, trazem uma outra memória da guerra, bem diferente da oficial (Cooksey, 2017). De novo um exemplo português: A Guerra Colonial não era assumida pelo Estado Português como sendo uma verdadeira guerra, mais como operações de limpeza. Não há uma memória visual oficial desta guerra, ao contrário de outras em que a fotografia foi instrumento de propaganda (Cardoso, 2014). A censura impedia a publicação de imagens da guerra que a imprensa nem produzia, 0 mesmo se passava com a ainda mais controlada televisão, ou os pequenos documentários que precediam os filmes apresentados no cinema. Fica hoje como memória visual dessa guerra a enorme quantidade de imagens fixas e em movimento produzidas por militares portugueses que estão guardadas nos álbuns de família.

Tal como a falível memória humana, a memória construída com a fotografia revelou ser seletiva. É seletiva no momento da recolha. Uma das maiores escolhas do fotógrafo é aquilo que quer fotografar, exercendo a sua capacidade de arbítrio sobre o que fica na memória. É seletiva a qualquer momento, já que as fotografias são, muitas vezes, deitadas fora, apagando-se essa memória.

A alegria da memória familiar que se constrói com a fotografia tem a ver com a escolha. As fotografias não são feitas de forma indiscriminada, são feitas em momentos escolhidos e esses são os que mais tarde se quer recordar. A escolha desses momentos é algo que mostra muito sobre essa sociedade, já que indica o que é, ou não, valorizado. Nos inícios da fotografia, e até à altura em que a posse de máquinas fotográficas se torna relativamente difundida, não é a memória de momentos, mas sim a de pessoas 
que se pretende conseguir. Mais tarde vai haver uma escolha de momentos que, por demonstrarem algumas constantes, acabam por corresponder a padrões sociais.

O facto de o processo fotográfico se ter tornado mais barato e simples fez com que se fosse passando da fotografia de uma pessoa para a fotografia de uma ocasião. Mesmo que Sontag defenda que "tudo no mundo pode ser objeto de fotografia" (Sontag, 1986: $103,155)$, isso aplica-se à segunda metade do Século XX, quando as fotografias ainda não eram um objeto tão banal. É mais correta a ideia de que fotografar é dar importância pelo que as ocasiões mais fotografáveis seriam, claro, as a que se conferia maior importância. Essas ocasiões, quer sejam de natureza pública ou privada, têm sido determinadas por convenções sociais, criando-se padrões a que as pessoas tomadas individualmente e as famílias "têm" que corresponder. Essa importância era, assim, mais uma questão social que individual.

Vão-se criando ocasiões da fotografia, além da maior e já referida, o casamento, também os batizados, comunhões, aniversários, carnaval e as cada vez mais importantes férias. A memória familiar constrói-se assim em torno de alguns momentos, supostamente os mais importantes e felizes. Claro que é necessário distinguir entre aquelas ocasiões em que se apelava ao fotógrafo profissional e as em que, a partir do momento em que a posse de um aparelho fotográfico se torna habitual, este era utilizado no registo desses momentos. Entre estes dois tipos de registo fotográfico há uma hierarquização, sendo o recurso a um profissional o sinal de uma importância muito grande da situação, ou de uma situação em que a uniformização de resultados é fundamental, como é o caso da fotografia de identificação.

O retrato acompanha momentos de transição e iniciação na vida das pessoas. Apesar de alguns momentos do percurso académico e profissional serem objeto de algumas imagens "obrigatórias", parece ser a família a conseguir ter o maior peso no retrato de estúdio. Dentro das ocasiões familiares no Norte parece haver um grande peso das questões religiosas que não parece ser acompanhado pelo Sul, mais carnavalesco. As crianças vão ganhando mais importância no retrato para se tornarem nos protagonistas das fotografias, a partir da segunda década do Século XX. É preciso notar que não eram fotografadas com muita frequência no século XIX, altura em que não era fácil, tecnicamente, fazê-lo. Bourdieu (1965), nos seus estudos sobre a fotografia, feitos na segunda metade do Século $X X$, considerou a existência de crianças como principal motivação para a fotografia.

Parece haver uma tendência para o crescimento da produção de retratos de crianças que embora já sendo frequentes durante o século XIX e até no início do $X X$, se tornam mais frequentes a partir dos anos 30. Também começa a fazer-se, nessa década, um tipo de retrato de bebés despidos que anteriormente era mais raro. Estes já são 
conhecidos desde os anos 1860, e foram populares até há não muito tempo. Os bebés tinham todas as condições para que o seu retrato fosse obrigatório, eram novos membros da família e passavam por mudanças rápidas, criando uma situação favorável ao hábito de colecionar. Devido a questões como a dificuldade de manter uma pose, ou aquelas originadas pela alvura das melhores roupas de bebé, estas não seriam muito apreciadas pelos fotógrafos que as desencorajariam. O crescimento desse tipo de retrato é também um sinal da importância crescente da infância.

Saindo da ideia de uma memória feita de momentos de felicidade, as fotografias de crianças mortas não parecem ser muito comuns, embora apareçam por vezes. Este tipo de imagem que, por exemplo em Espanha, foi muito popular, correspondia à ideia de que era necessário ter um registo fotográfico dos que tinham morrido sem ser fotografados, tornava a fotografia em algo de necessário, no mesmo sentido que o batismo. Claro que a necessidade se colocava em termos de memória familiar e não de salvação da alma.

Também é possível encarar estas imagens do ponto de vista das atitudes em relação à morte. A fotografia, que alguns autores têm relacionado com a morte, é feita para que quem faleceu pareça estar vivo, uma forma de negação da morte, a atitude dominante na sociedade. Estas fotografias, que em Portugal costumam estar limitadas aos bebés que morreram antes de ter ocasião de se deslocar ao estúdio do fotógrafo, mostram as crianças como se dormissem, uma semelhança muito grande com o "sono eterno", um dos eufemismos para a morte. Nos países hispânicos, e mesmo nos Estados Unidos, essas fotografias são muito mais frequentes que em Portugal.

A fotografia familiar de amadores, em crescimento rápido a partir dos anos 1880 e que predomina na imagem fotográfica a seguir à primeira guerra mundial vai criar toda uma nova ocasião de que é necessário um registo para a construção de uma memória familiar. A mobilidade que as máquinas fotográficas permitem é muito maior do que quando as ocasiões tinham que ser fotografadas num estúdio.

As novas ocasiões da fotografia vão, assim, ser aquelas em que há atividades desenvolvidas no exterior. As férias tornam-se no principal motivo da fotografia, o que pode ser comprovado pelo facto de a Kodak, na revista llustração do final dos anos 20 , só fazer publicidade nos meses de Verão e por altura do Natal. Nos próprios anúncios predominam as situações de férias, com praia e campo.

Estes anúncios deveriam ter algum efeito, já que as fotografias que se encontram em coleções familiares dessa altura refletem essas ocasiões. Tal como noutras situações, estas imagens centradas nas férias vão-se espalhando das classes superiores para as menos ricas. As fotografias de D. José Gil, já tinham uma grande componente de férias e viagem nas últimas décadas do Século XIX. 
A fotografia reflete, com as suas ocasiões, um padrão familiar que se vai centrando mais nos filhos e em que as questões do casamento se vão tornando mais relevantes. Este padrão repete-se dentro de um país e tem modelos internacionais.

O álbum que é uma recolha sistemática de imagens do grupo, das suas atividades, passa dos grupos familiares para outros grupos da sociedade, num movimento que tende a alargar-se. Grupos de carácter profissional, desportivo, político ou associativo passam a fazer-se fotografar enquanto grupo. Melhor exemplo são as imagens de todos os membros de um determinado ano de um curso universitário, em voga, pelo menos, dos anos 1880, aos anos 1930.

\section{Sistematizações em sociedade}

A ideia de sistematização, tão comum no Século XIX, e que tem a sua expressão na organização de coleções, teve alguns efeitos particulares na fotografia. Cria-se a ideia de que, por meio da fotografia, se pode fazer um registo sistemático daquilo que estava ameaçado de desaparecimento. Há tentativas de registo sistemático de monumentos com a "Mission Heliographique" ainda dos anos 1840, em França, com seguimentos um pouco por todo o lado. Em Portugal verifica-se sobretudo a busca de temas etnográficos, havendo tentativas relativamente sistemáticas de registo de usos e costumes locais, em trabalhos realizados por simples amadores ou etnólogos como Rocha Peixoto.

Como já se referiu, com a fotografia criou-se um objeto cuja finalidade assumida é a criação de uma memória. Virá, mais facilmente, ao pensamento a ideia de que se está perante uma memória exclusivamente familiar, a criação do álbum e a circulação das fotografias dentro da teia de relações da família sugerem-no, mas isso não corresponde inteiramente à realidade. Vários grupos não familiares tendem também a utilizar a fotografia dessa mesma forma. Há nesta utilização da fotografia uma carga afetiva forte, mesmo fora das relações familiares, com referência a uma memória coletiva (Sá, 1986). A fotografia também parece ter alguma capacidade para suprir essa falta de memória coletiva, segundo Sontag (1986: 24), seria essa a razão para que americanos e japoneses a ela se dediquem de forma tão sistemática.

Todos estes tipos de fotografia correspondem a uma ausência de diferenciação entre a fonte e os recetores da comunicação (Sá, 1986), mesmo se a fotografia só existe em função de uma difusão e, logo, de um recetor (Gervereau, 1998). 


\section{Uma memória da sociedade}

A partir da popularização da imprensa ilustrada por fotografias, essas imagens cujo fim era imediato e efémero, dar a notícia no dia, ou na semana seguinte tornaram-se numa certa forma de memória da sociedade, ou pelo menos a fazer parte dela. O número de recetores para uma mesma imagem crescia enormemente. Os jornais compreenderam esse facto bastante cedo, tornando-se a fotografia a sua imagem predominante a partir da $1^{\text {a }}$ Guerra Mundial, e estabelecendo e organizando os seus arquivos na previsão de que uma fotografia que era utilizada num determinado dia o poderia voltar a ser.

Com a fotografia de imprensa, destinada à função imediata de reportar a notícia, vai surgir uma memória dos acontecimentos e das pessoas de uma determinada sociedade, num determinado tempo. Pode-se pensar que essa memória não é muito diferente, em relação às pessoas, do que já se fazia há décadas com as Cartes de Visite de celebridades, porém a sua difusão é muito mais alargada.

Não é só a memória familiar que é seletiva, a memória da sociedade tem demonstrado sê-lo ainda mais. A reconhecida pouca fiabilidade da memória humana e a reconhecida objetividade da memória fotográfica têm possibilitado o uso da fotografia como forma de falsificação da história, ou pelo menos como forma da sua legitimação. A rescrita da História da Revolução Russa não teria credibilidade se não fosse completada pela manipulação da imagem fotográfica, mas retomaremos este assunto.

Se este pequeno aspeto do terror estalinista é conhecido, não é o único. Mais de cem anos de imprensa ilustrada dariam exemplos de enquadramentos de imagens feitos de forma a retirar personagens incómodas, suficientes para muitos volumes. Não se chega, de modo geral, ao retoque da imagem, já que um código de objetividade o inibe (Le Marec, 1985). A imagem digital e a facilidade que existe em a alterar têm sido um motivo de polémica na fotografia de imprensa, tendo havido premiados desclassificados em concursos prestigiosos da imprensa por via dessa manipulação de imagem.

Este expediente tem resultado pelo mesmo motivo: A imagem fotográfica é credível em relação ao acontecimento que é suposto registar com objetividade.

A construção de memória tem sido um objetivo confesso da fotografia, até enquanto indústria, ao longo de mais de 150 anos. A grande diferença que a fotografia introduz é a facilidade com que esta memória é construída, criando a possibilidade de que se construa uma memória que tem uma base alargada na sociedade e também uma base alargada de acontecimentos. Esta construção de memória surge, precisamente, no momento em que as sociedades começam a sofrer um rápido processo de transformação, que também implica uma alteração das ocasiões consideradas relevantes para a preservação de memória no sentido do seu alargamento. 


\section{Lugares e discursos da memória}

$\mathrm{O}$ arquivo, os monumentos, os programas escolares, a toponímia, a arte pública, em especial a estatuária são locais da memória. Da memória coletiva, de uma memória coletiva oficial. São os locais que escapam ao esquecimento, o que pode acontecer por esforço oficial, ou pela ligação afetiva. Há algumas décadas esta ideia foi objeto de uma obra monumental dirigida por Pierre Nora (1986) com uma inventariação desses lugares em França.

Tal como a própria memória e porque dela são instrumentais esses locais também se alteram com o tempo e as realidades históricas. Também se criam e se projetam para as realidades que pretendem evocar. Há um grande peso oficial nestes locais, é o poder que tem a capacidade de construir monumentos, de colocar nomes das ruas, mas estas memórias podem ter um lado de iniciativa popular mais ou menos estruturada. A viragem do século XX é marcada pela edificação de estátuas por subscrição pública. Camões, Afonso Henriques ou os Restauradores de 1640 têm estátuas em Lisboa que foram financiadas por este método. O mesmo se passa noutras cidades. Por vezes estes locais podem surgir de forma informal. Junto à estátua do Dr. Sousa Martins há um movimento de fazer promessas e deixar recordações, como se fosse um santo, o mesmo se passa com o Padre Cruz em Alcochete.

Esses locais não são forçosamente os mais significativos, ou os "verdadeiros". A sua importância constrói-se na narrativa, como escrevia Maurice Halbwachs: "Os lugares sagrados comemoram (...) não factos certificados por testemunhos contemporâneos, mas crenças nascidas porventura longe desses lugares, e que se fortaleceram ao enraizarem-se aí" (Vidal-Naquet, 1993: 29-30).

A memória pessoal e individual tem também os seus lugares, alguns confundem-se com os da memória coletiva, outros são os que permitem a recordação de memórias e momentos pessoais. Também podem ser objetos, o "souvenir" é um objeto que se produz com este fim. Porém o mais importante dos locais da memória privada e familiar é o álbum de fotografias que vai acumulando momentos ao longo do tempo para, segundo o slogan da Kodak, "mais tarde recordar".

As memórias não controladas oficialmente podem ser preciosas quando se sai da história mais institucionalizada. Miriam Halpern Pereira defende que para a "História vista de baixo", "O problema das fontes coloca-se de forma dramática quando se querem ouvir as vozes dos desfavorecidos e dos marginalizados. O documento escrito apenas permite uma visão de cima para baixo" (Pereira, 2010: 40).

Nova história necessita de novas fontes e da incorporação das memórias e locais de memória privados. As recolhas orais são o objeto mais óbvio, mas outros materiais, 
nomeadamente as fotografias são igualmente importantes. Esta memória será menos oficial e sobretudo mais diversa.

\section{Memória, um terreno disputado}

Se tivermos em conta os grandes grupos, como os estados ou as nações, pode haver memórias que sejam comuns e partilhadas e outras que não só não sejam coincidentes, como sejam contraditórias ou antagónicas. Isso é mais acentuado quando há acontecimentos traumáticos recentes e tende a atenuar-se com o tempo.

A história recente de Portugal dá bons exemplos, uma mesma realidade pode ter designações diferentes: descolonização exemplar ou vergonhosa; independência das colónias, ou abandono dos territórios ultramarinos. Correspondem forçosamente a uma memória diferente para um militante de esquerda, para alguém que estivesse próximo da idade de ir combater, ou de uma pessoa que tivesse regressado a Portugal (ou à metrópole) em função desse processo. 025 de Novembro pode ser visto como o regresso ao espírito do 25 de Abril, ou como a sua destruição. Salazar ou Cunhal serão santos ou demónios, conforme o posicionamento político. Outras figuras bem conhecidas há 40 anos, estão hoje quase esquecidas. Mário Soares, de certa forma o vencedor do processo, já que o modelo final é mais próximo do seu, é para as gerações que não viveram os anos de 74/76 a figura mais conhecida. Também tem sido a mais mediatizada e presente nos manuais escolares. Há muito mais fotografias de Mário Soares na nossa memória coletiva do que de qualquer outra personagem.

A memória coletiva é pouco consensual para muitos acontecimentos recentes, e adaptase às necessidades e interesses do momento. É conhecida a remoção da fotografia de Freitas do Amaral do panteão de dirigentes do CDS quando este foi ministro de um governo socialista.

O caso extremo do apagar da memória para a adaptar às necessidades políticas é o que se passou no regime estalinista, em que os dirigentes bolcheviques iam sendo removidos das fotografias, ou seja da memória, à medida que iam caindo em desgraça. Este é um facto que por tão conhecido entrou na memória coletiva (aqui vista como uma memória supranacional), talvez conflitue com a memória coletiva daquele grupo político específico.

Num daqueles diálogos cruzados entre o privado e o público os que eram apagados das fotografias oficiais, mais tarde, também o eram dos álbuns privados. Ter fotografias destas pessoas implicava alguns perigos (King, 2014). Apagar das memórias privadas e familiares e sabendo que a memória se recompõe é garantia de não regresso à 
memória coletiva. Porém esses regimes políticos caíram e não só o presente político foi alterado, como a memória coletiva foi recomposta. Heróis passaram a vilãos e viceversa. A imagem dos dirigentes do regime deposto foi uma das primeiras vítimas da queda dos regimes de Leste. Estes dirigentes eram omnipresentes na estatuária em espaço público, era uma das formas de dominação ideológica destes regimes. Com a queda dos regimes caíram as estátuas, que se tinham tornado símbolos de opressão. Menos dramática, mas muito rápida foi a mudança de nomes ligados à ditadura em ruas portugueses e, mais polémica, na ponte que deixou de ser Salazar, para ser 25 de Abril. A recomposição da memória coletiva em países dominados por ditaduras foi acompanhada de reabertura de arquivos. O conhecimento dos arquivos da URSS e de outros países não produziu alterações significativas no conhecimento que existia da época, pelo menos no Ocidente. Porém, todo o terror do período estalinista também tem os seus revisionistas, Ludo Martens (1994) e Domenico Losurdo (2008), entre outros. Os argumentos são decalcados dos dos revisionistas do nazismo, nomeadamente a impossibilidade técnica da existência de tantas mortes (Vidal-Naquet, 1995). Sublinhese que os revisionistas do estalinismo têm a grande vantagem de não ter em seu desfavor as fotografias dos campos de morte feitas na altura da libertação e muito difundidas, entretanto. Não há muitas fotografias do Goulag.

O afastamento temporal tornaria, em princípio, a memória mais consensual, mas há assuntos que mesmo sendo de um passado remoto continuam a suscitar divisões. Em outubro de 2017 uma manifestação de grupos antirracistas junto à estátua do Padre António Vieira, em Lisboa, é impedida por uma concentração de neonazis. Não estava em causa só o Padre António Vieira, mas a memória da escravatura e o passado colonial português.

Memórias pessoais e familiares também podem passar por destruições e reconstruções. Separações e divórcios levam à reconstrução do álbum de família, fotografias que desaparecem complementam o afastamento emocional, em casos extremos a fotografia continua e alguém é retirado dela.

\section{Convergência de arquivos}

A existência de um poder local mais próximo das populações, a tentativa de encontrar identidades locais e de grupos, tem levado a que arquivos municipais e outros se interessem não só pelos documentos administrativos, como por aspetos variados da vida local que não estavam presentes no tradicional arquivo municipal. Este arquivo tinha uma função utilitária e administrativa e começou a considerar-se necessário que pudesse guardar (é a função do arquivo) e mostrar mais da localidade para os seus 
próprios habitantes e visitantes. Há também uma função educativa, sendo as escolas um dos principais destinatários.

Não é de estranhar que este movimento se tenha iniciado a partir do momento em que o poder local se estabiliza, tendo uma autonomia política que na ditadura não existia. É contemporâneo e ligado ao interesse na história local de que se alimenta e que alimenta. Os arquivos municipais eram, tradicionalmente, compostos pelos documentos administrativos produzidos pela própria câmara. Mas os arquivos e museus começaram a procurar outro tipo de documentos, aqueles que estavam com as pessoas e famílias, o arquivo familiar começa a entrar no arquivo local e no museu municipal. Pode-se ler no site da Câmara Municipal de Almada: "O Museu da Cidade abriu ao público a 1 de Novembro de 2003 como casa da história e memórias da cidade, da aprendizagem e da experiência urbana do concelho" ${ }^{1}$. Ou para um dos núcleos do Museu Municipal de Alcochete: "Um pequeno, mas valioso, conjunto de objetos representa importantes momentos da História do Concelho. Uma significativa coleção etnográfica deu origem a diversas áreas de exposição" ${ }^{2}$. Para o Museu Municipal do Cadaval é explícita a referência às fotografias: " Num conjunto de fotografias antigas pode ver-se como era a vila do Cadaval e a sua vida cultural e recreativa, desde o início do século XX"3. Ou ainda em Vale de Cambra que tem uma grande coleção de fotografias:

Para além da documentação produzida pela Câmara Municipal, o Arquivo está dotado de um vasto espólio, constituído por diversos fundos documentais - (...) as coleções de fotografia Foto Sousa e Foto Central, entre outros -, cujo documento mais antigo data de $1755^{4}$.

Aquisições, doações, empréstimos para digitalização têm sido os métodos mais comuns. É frequente que arquivo e alguns materiais de empresas que fecham entrem no arquivo ou museu municipal. Os materiais que entram nos arquivos são variados, de instrumentos de trabalho e coleções a fotografias. Isto mostra uma vontade deliberada de museus, arquivos e particulares de fazer entrar a memória individual e familiar na memória coletiva.

\footnotetext{
${ }^{1}$ Retirado de http://www.malmada.pt/portal/page/portal/MUSEUS/MUSEU_CIDADE/? mus $=1 \&$ mus_museu_cidade $=4963003 \&$ cboui $=4963003$, consultado a 2017-10-08

${ }_{2}^{2}$ Retirado de http://www.cm-alcochete.pt/pages/205, consultado a 2017-10-08

${ }^{3}$ Retirado de http://www.cm-cadaval.pt/museu-municipal, consultado a 2017-10-08

${ }^{4}$ Retirado de http://www.cm-valedecambra.pt/pages/423, consultado a 2017-10-08
} 


\section{Arquivo virtual}

Estes museus e arquivos têm trabalhado no sentido da divulgação dos seus materiais. Muitos vão ao ponto de colocar documentos e fotografias online. Caso do citado Arquivo Municipal de Vale de Cambra. Porém há outras formas mais difusas e informais.

Portais de partilha e armazenamento de imagens foram capazes de abarcar muito rapidamente tipos diferentes de imagem, tipos diferentes de utilizadores e grupos distintos. Utilizadores individuais constroem os seus diários, famílias partilham os seus momentos, associações mantêm o contacto entre os seus associados, localidades constroem a sua história. É um processo muito participado, muito democrático, já que aberto à colaboração de todos. Serve para imagens antigas, inúmeras povoações têm o seu grupo de partilha, geralmente iniciado por uma pessoa, mas apropriado por outras. A difusão é muito grande, mas sendo aparentemente estas redes muito volúveis é o futuro que está em causa. Não sabemos o que se irá passar nos próximos dez anos, muito menos daqui a uma geração. Esse problema de arquivos na internet também se coloca com arquivos físicos digitais. Qual será a durabilidade dos suportes, a obsolescência dos sistemas? Parece certo que ao contrário de arquivos antigos estes não se manterão sem esforço deliberado.

\section{Novos arquivos para uma nova história}

Tenho o ponto de vista do historiador, as fontes são o material da história e condicionam a história que pode ser feita. O alargamento da base dos arquivos cria novas possibilidades para o historiador. Além do documento administrativo, a incorporação de materiais provenientes de arquivos familiares, onde as imagens são muito importantes, permite chegar a grupos ausentes do arquivo tradicional, permite chegar a aspetos da vida que têm estado relativamente ausentes da história. Nova História, com o seu alargamento de fontes; "História vista de baixo" mudando o enfoque das elites para as pessoas comuns: não são possíveis sem que o arquivo tradicional possa incorporar o arquivo pessoal e familiar. Sem que memória individual e memória coletiva se cruzem.

\section{Referências bibliográficas}

Barthes, R. (1981). A Câmara Clara. Lisboa: Edições 70.

Bourdieu, P. (1965). Un Art Moyen. Paris: Minuit.

Briggs, A. (1989). A Victorian Portrait, Victorian Life and Values as Seen throught the Work of Studio Photograpers. Nova lorque: Harper \& Row. 
Cardoso, D. M. C. (2014). Imagem e propaganda em Portugal durante a Segunda Guerra Mundial. Dissertação de mestrado. Lisboa: ISCTE-IUL.

Cooksey, J. (2017). The Vest Pocket Kodak and the First World War. Lewes: Amonite Press.

Corbin, A. (1990). Os Bastidores. In P. Aríes \& G. Duby (Dir.), História da Vida Privada (pp. 413-611). Lisboa: Afrontamento.

Fabri, P. (1997). Image et Politique. Actes Sud, sl..

Felman, S. (1999). Silence de Walter Benjamin. Les Temps Modernes, 606, 1-46.

Ferguson, N. (1997). Virtual History. Londres: Papermac.

Freund, G. (1974). Photographie et société. Paris: Seuil.

Gervereau, L. (1998). Un Image ne Parle Pas. In F. Docquiert \& F. Piron (Dir.), Image et Politique (pp. 47-58). Paris: Actes Sud.

Gherardi, S. (1995). Gender Symbolism and Orgazational Cultures. Londres: Sage.

Halbawachs, M. (s.d.). On Collective Memory. Chicago: University of Chicago Press.

Hirsh, M. (1997). Family Frames, Photography, Narrative and Post-Memory. Cambridge: Havard University Press.

King, D. (2014). The Commissar Vanishes: The Falsification of Photographs and Art in Stalin's Russia New Edition. Londres: Tate.

Le Marec, G. (1985). Les Photos Truquées. Paris: Ed. Atlas.

Lequin, I. (1983). Histoire des Français, XIXéme, XXéme Siècles, La Société. Paris: Armand Colin.

Linkman, A. (1993). The Victorians - Photographic Portraits. Londres /Nova lorque: Tauris Parque Books.

Losurdo, D. (2008). Stalin. Storia e critica di una leggenda nera. Roma: Carocci.

Martens, L. (1994). Un autre regard sur Staline. Anvers: EPO.

Martin-Fugier, A. (1990). Os Ritos da Vida Privada Burguesa. In G. Duby \& M. Perrot, História da Vida Privada, $4^{\circ} \mathrm{Vol}$ (pp 193-285). Lisboa: Afrontamento.

Nora, P. (1978). Memória Coletiva. In Le Goff, et al. (dir.), A Nova História (pp. 451-454). Coimbra: Almedina.

Nora, P. (ed.) (1986). Les lieux de mémoire. Paris: Gallimard.

Osherson, D. et. al. (Eds.) (1990). Visual Cognition and Action, Vol 2.. Cambridge, Londres: MIT Press.

Pereira, M. H. (2010). O Gosto pela História, Percursos de História Contemporânea. Lisboa: ICS. 
Pinheiro, N. (1997). As Classes Populares na Fotografia em Portugal no Início do Século $X X$. Lisboa: ISCTE.

Sá, C. P. (1998). Núcleo Central das Representações Sociais. Petrópolis: Vozes.

Sontag, S. (1986). Ensaios sobre Fotografia. Lisboa: Dom Quixote.

Tagg, J. (1988). The Burden of Representation, Essays on Photographies and Histories. Houndmills e Londres: Macmillan.

Tenfelde, K. (Dir.) (1994). Fotografie und Geschichte in Industriezeitalter. Munique: Verlag C.H. Beck.

Thompson, E. P. (1963). The Making of the English Working Class. London: Victor Gollancz Ltd.

Vidal-Naquet, P. (1991). A Democracia Grega, Ensaios de Historiografia Antiga e Moderna. Lisboa: Dom Quixote.

Vidal-Naquet, P. (1995). Les assassins de la mémoire. Paris: Le Seuil.

Nuno Pinheiro é investigador Associado do CIES-IUL. Doutorado em História Moderna e Contemporânea pelo ISCTE (2003). A sua investigação tem sido centrada na utilização da imagem fotográfica como fonte histórica e nos papeis sociais e históricos da fotografia. Autor de quatro livros e cerca de trinta artigos e capítulos de livro, prepara um trabalho sobre os primórdios do fotojornalismo. 